\title{
National Versus Private-Label Brands: Dynamics, Conceptual Framework, And Empirical Perspective
}

\author{
Elias G. Rizkallah, La Sierra University, USA \\ Heather Miller, La Sierra University, USA
}

\begin{abstract}
Motivated by profits and their growing power in the marketplace, retailers have been expanding their private-label brands to include more categories of consumer products and differentiation on quality to reach different consumer segments. This global phenomenon is adversely impacting the performance of national brands, thus creating a conflict between two powerful parties manufacturers of national brands and their large retailers who are supposed to be their helping hands in the marketplace.

In this paper, the authors develop a conceptual framework, which captures the complexity and multidimensionality of the situation - the stakeholders involved, the interest and power of each, the relationships among them, various strategies they employ, and the outcomes of the conflict. Several hypotheses were examined and tested through the empirical part of this study; for example, would the powers of these parties determine who is the loser and who is the winner or will the verdict be in the hands of the consumers? The study surveyed 281 consumers to assess their attitudes toward and preferences of store brands versus national brands across product categories and the underlying motivations. The paper concludes with recommendations for retailers and national brand manufacturers to win the hearts of consumers rather than exhaust their resources in the conflict.
\end{abstract}

Keywords: National Brand; Private Label/Store Brand; Manufacturer-Retailer Relationship; Product Categories; Consumer Behavior

\section{INTRODUCTION}

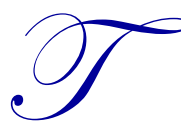

he global growth of market share of store brands, or private labels, is no secret. This growth, although at different market penetration rates in different countries, has been overwhelmingly cited in the topic-related literature. The magnitude of the surge in store brands in recent decades is alarming to most manufacturers of national/global brands and has warranted an impressive number of research studies seeking to understand the dynamics of the phenomenon in which stakeholders are involved, their strategies and behaviors, the underlying factors, and the impact on their performance.

Motivated by profits and their growing power in the marketplace, retailers have been expanding over the last few decades and it seems they will continue to expand in the future. This trend is a result of four major developments: 1) the increase in size and power of retailers, 2) their global expansion, 3) applications of advanced technologies, and 4) the use of modern marketing strategies. Because size translates into power, the large retailers, in particular, are getting closer to their customers via the latest technologies, are stepping outside their playing box for more integration, are sharpening their competitiveness, and are exploiting customer store loyalty as well as their increased knowledge and awareness of today's consumers - to introduce their own private label brands and achieve their goals. Thus, retailers are able to influence manufacturers - not only smaller manufacturers, but the large ones as well. As a result, manufacturers are feeling the heat of private label brands and cannot sit still under the 
circumstances, seeing their shelf space decrease, market share erode, profits diminish, and bargaining power weaken - and thus are also getting more aggressive in their strategies and tactics.

In this research, the authors attempt to develop a comprehensive conceptual framework that integrates many of the research findings in the literature. Also, they examined certain aspects of the situation via an empirical research study of 281 consumers. This attempt was to verify some of the hypothesized relationships and shed light on the complexity and multidimensionality of this phenomenon.

The purpose of this study is to uncover the factors favoring store brands and those favoring national brands and how those factors impact the consumer decision-making processes and attitudes toward private-label versus national brands. It seeks to understand, for example, what the underlying reasons for consumer preferences are; whether those preferences are stable or if they change over different product categories, different economic conditions, and different consumer characteristics; and whether or not consumers believe the quality of store brands is comparable to that of national brands, etc. In the final analysis, it seeks to know how important the power of the consumer is in the outcome of this battle of the brands. It is hoped that uncovering these dynamics will enlighten both national brand manufacturers and retailers to make better decisions rather than exhausting their resources in the battle.

The paper draws some recommendations and conclusions that may benefit all stakeholders, but also notes the limitations of this research attempt - given it is based on respondents' self-reporting rather than observations and/or industry data, small sample size, and limited geographic scope of the population frame.

\section{LITERATURE REVIEW}

Private labels have become a formidable adversary for national brands amid the expanding power and influence of retailers in recent years. Contemporary research on this topic examines notable risks faced by the major stakeholders (consumers, manufacturers, and retailers), strategic recommendations for both manufacturers and retailers as they contribute toward the evolving relationship between national brands vs. private labels, and the recognition of need for further research with the aid of a more holistic conceptual framework.

Consumers' purchasing decisions are at the heart of the ongoing tug-of-war between national brands and private labels. Simplistic categorization of modern-day consumers as "brand seekers" or "private label seekers" (Parker, 2006) is no longer an accurate description, as consumers have become more savvy than ever in their product selection process. In fact, their preferences may vary widely across the full spectrum of product categories and pricing segments, as both national brands and private labels strive to deepen market penetration and fortify their pricing and promotion strategies. While consumers generally stand to benefit from escalated competition between national brand manufacturers and private label retailers, consumers also face distinct risks within this competitive arena. For example, aggressive advertising efforts by both manufacturers and retailers may stimulate and reinforce the notion that higher price yields better quality (Steenkamp et al., 2010) and potentially distort the consumers' understanding of actual quality. Another example of consumer risk may involve the inadvertent incentive for retailers to intercept the manufacturers' promotional efforts targeted at the consumers; the greater the price gap between the national brands and the private labels, the more the retailers stand to profit (Batra, 2000).

Manufacturers of national brands have faced particularly challenging risks as private labels' growth has accelerated. Collectively, the expansion of private labels across different pricing segments (e.g. economy vs. premium products), new distribution channels (e.g. Costco, Target, and Wal-Mart's integration of grocery segments), and new product categories (e.g. from staple foods to health and beauty products) have introduced a significant pressure on the profitability of national brand manufacturers (Quelch \& Harding, 1996). Left unattended, erosion of profitability is all but certain as private labels continue to attract customers and garner momentum. Overly aggressive tactics, however, may sour the manufacturers' partnership efforts with the retailers, which are integral to the manufacturers' long-term profitability (Shetty \& Manoharan, 2012). Fine-tuning of these competing interests is an ongoing dilemma for national brand manufacturers and will present noteworthy risks in their strategic endeavors. 
Retailers also face certain risks despite the relatively favorable performance of their private labels in comparison with that of national brands. One prominent risk is that the success of private labels is inversely correlated with macroeconomic expansions, as consumers typically exhibit value-seeking behaviors within periods of recessionary contractions (Lamey et al., 2007; Quelch \& Harding, 1996; Seuffert, 2009). Although studies have shown that gains in private label market share during economic contractions are lasting in nature, the reluctance of many brand managers to proactively invest in long-term profitability with opportunistic marketing strategies introduces a troublesome obstacle (Lamey et al., 2007). A related risk is that the consumers' private label attitude is strongly influenced by the store image (Semeijn et al., 2004; Richardson et al., 1996). Since improving the overall store image involves large-scale enhancements to many moving parts such as customer service, merchandise quality, and store environment, it also heavily depends on the willingness of brand managers to sustain a more long-term focus in managing their private labels. Another major risk for private labels is self-cannibalization during pricing segment expansions (Geysken et al., 2010). While some self-competition is inevitable as a trade-off for generating flanking products (e.g. economy vs. premium products) in competing national brands, the risk of significant declines in individual product line profitability is real and should be monitored judiciously. Brand loyalty, however, may present the greatest risk for retailers of private labels (Goldsmith et al., 2010). Historically, national brands have enjoyed a much greater consistency in their consumers' positive attitudes, preferences, and repurchases arising from brand loyalty. Studies conducted under blind vs. non-blind conditions have revealed brand loyalty as a major factor in consumers' purchasing decisions (Breneiser \& Allen, 2011), indicating that perceived quality - as opposed to actual quality - is often more influential in the purchasing process; this poses an added risk for private labels as a competitor for the same pool of consumers. Lastly, retailers of private labels share the similar possibility of harming their partnership with the manufacturers of national brands in parallel with the employment of more aggressive marketing tactics. One of the key drivers of consumers' private label selection process ironically involves the highlighting of the pricing and value differentials between private labels and national brands (Parker, 2006); in other words, the existence of national brands is essential to the perception - and hence, the associated success - of private labels as bargain deals. Furthermore, the marketing efforts undertaken by national brands frequently benefit the overall product category, including the associated private labels (Parker, 2006). Clearly, such synergisticantagonistic relationship between private labels and national brands is remarkably complex in nature.

Topic-related literature cites numerous research-based recommendations for manufacturers. Manufacturers are encouraged to continuously innovate in their national brand product development (Ashley, 1998; Corstjens \& Lal, 2000; Shetty \& Manoharan, 2012). For example, manufacturers may add unique components and/or ingredients to their national brands that may be difficult, costly, and/or impractical for the retailers to emulate in their private label offerings (Shetty \& Manoharan, 2012). This strategy functions to raise the barrier of entry for copycat products including, but not limited to, private label products. Manufacturers are well equipped for such ongoing innovations primarily due to their industry expertise, despite the rising power of retailers in their ability to imitate the national brands.

In formulating and advancing comprehensive marketing strategies, manufacturers should exercise caution not to sacrifice quality (Horvat, 2011; Shetty \& Manoharan, 2012). Modern-day consumers are more qualityconscious than ever and are likely to be drawn toward private labels with comparable quality in response to noticeable declines in the quality of national brand products. Accordingly, maintenance of and/or improvements in quality over time are essential and should not be a source of compromise for manufacturers.

Effective marketing communication will be especially critical for the future success of national brand manufacturers (Ashley, 1998; Erdem et al., 2004; Liu \& Wang, 2008; Corstjens \& Lal, 2000; Shetty \& Manoharan, 2012). Studies have demonstrated that consumers tend to perceive higher uncertainty risk in private label products due to their relative lack of clear and objective information. By educating consumers via advertisements focusing on the defining characteristics of their national brand products, manufacturers may further widen the uncertainty risk gap in the minds of consumers, thereby increasing their anxiety regarding untested private labels.

Studies have confirmed the conventional wisdom that consumers seek out "bargain deals" with a greater focus on utilitarian needs during economic recessions (Seuffert, 2009; Lamey et al., 2007). As the macroeconomic recovery progresses, however, there is a noticeable reversal in consumer focus back onto more hedonic needs combined with a greater willingness to spend money (Shetty \& Manoharan, 2012). Highlighting such hedonic 
appeals of national brand products will therefore help differentiate the national brands from the competing private labels.

Manufacturers may also choose to employ two types of preemptive strikes against retailers. The first approach would be to introduce "value flankers" to capture the value gap between the existing national brand product and the retailers' private label product (Shetty \& Manoharan, 2012; Geyskens et al., 2010). The advantage here is that this tactic would reduce the perceived "value differential" in the eyes of consumers, thus rendering the competing private label product less attractive. The alternative approach - though conceivably risky - might be for the manufacturer to form a direct partnership with the retailer in producing the private label (Parker, 2006; Quelch \& Harding, 1996; Shetty \& Manoharan, 2012). Some self-cannibalization and/or loss in profitability may be unavoidable in this manner, but this method may utilize otherwise unused manufacturing capacity, enhance industry experience, and decrease fixed cost per unit of production (Quelch \& Harding, 1996). With objective calculations and analyses under consideration, this partnership - albeit atypical - may be a profitable venture for the manufacturer.

For retailers, the following are some research-based recommendations from the literature. Although the traditional appeal of private labels has been its $15-40 \%$ lower pricing point in comparison with national brands (Ashley, 1998), retailers should no longer place their emphasis on price alone; consumer focus in the recent years has been on value (encompassing the consumers' perception of quality) rather than price (Pandya \& Joshi, 2011; Horvat, 2011; Corstjens \& Lal, 2000). Hence, it is recommended that retailers aim to increase the perceived value per dollar of consumer spending in order to enhance the attractiveness of their private labels.

Research has isolated distinctive packaging as the most potent driver of consumers' willingness to pay rooted in the perceived quality gap (Steenkamp et al., 2010). Although packaging alone may be an easy target for rivals' mimicry, private labels may indeed benefit by using the package as an advertising tool to minimize the uncertainty risk for consumers (Shetty \& Manoharan, 2012). This may be achieved by maximizing the inclusion of objective information detailing product ingredients or specifications, production quality, and/or third-party endorsements.

As with the recommendation for manufacturers, retailers are also encouraged to explore untapped value segments via introduction of economy, standard, and/or premium private labels (Geyskens et al., 2010). Collectively, such family of private label products may not only capture more profitability within the product line, but also enhance the overall store image (Pandya \& Joshi, 2011; Liu \& Wang, 2008). For private labels, better store image is strongly associated with more positive attitude (and hence greater receptivity) toward private labels, completing a positive feedback cycle (Liu \& Wang, 2008; Corstjens, \& Lal, 2000).

Lastly, private label partnership with national brand manufacturers is also recommended for retailers (Parker, 2006; Quelch \& Harding, 1996; Shetty \& Manoharan, 2012). As it was with the manufacturer, this risky strategy may possibly yield diminished profitability for the retailer. The potential upside, however, is that the retailer may utilize the full extent of the manufacturer's industry expertise in producing the private label, all the while maintaining a positive long-term relationship with the manufacturer.

Thus far, research findings have revealed various facets of the relationship between national brands vs. private brands. Many of these studies have been somewhat limited in scope, however, lacking a more holistic perspective on the situation. The authors were motivated by this observation to develop a comprehensive conceptual framework examining the multidimensionality of this dynamic.

\section{CONCEPTUAL FRAMEWORK}

Inspired by the massive amount of multi-faceted research attempts on private-label brands, their success and growth in recent decades, reasons for this success, and what manufacturers of national brands can do in light of this challenge, etc., the authors decided to present what they know so far from previous studies in the literature on the topic, along with their insights, into a comprehensive and integrative conceptual framework (Figure 1) to demonstrate the dynamics of this global phenomenon. The framework identifies the entities involved 
(manufacturers, retailers, consumers), their characteristics and motivations, relationships among them, the influence of environmental factors (e.g. economic conditions, social/cultural factors, general consumer confidence, etc.), and the behavior, strategies, and performance of these entities across product categories. It is to be noted that the current research study was designed to verify some of these dynamics and their impact on the consumer choice.

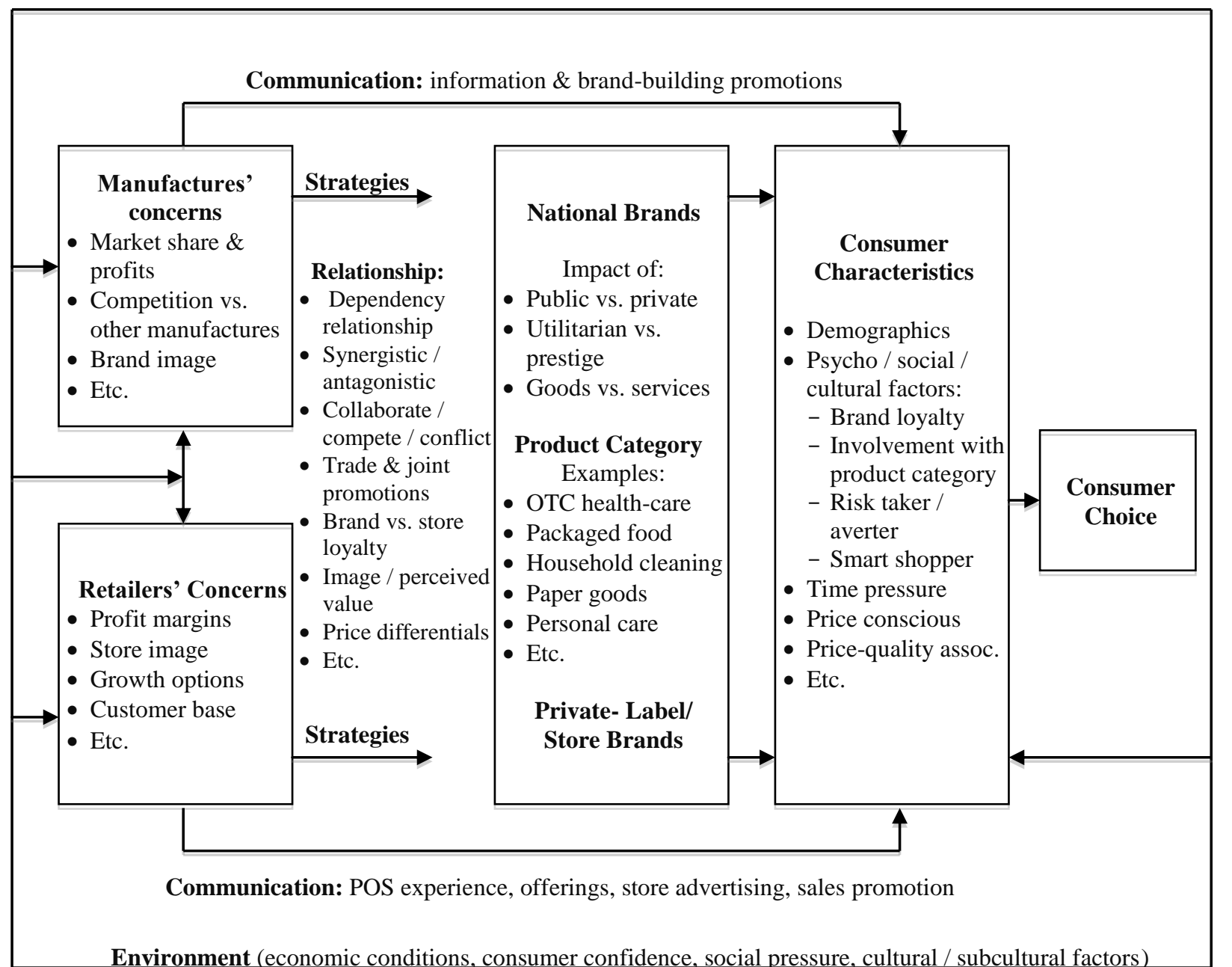

Environment (economic conditions, consumer confidence, social pressure, cultural / subcultural factors)

Figure 1. Conceptual Framework: Dynamics of National vs. Private-Label Brands

Concerns and strategies of manufacturers of national brands include:

- $\quad$ Their power in the marketplace - competitive advantages, market share, etc.

- $\quad$ Bonding with the channel of distribution to support their presence in the market and serve the targeted customers

- $\quad$ Concerns about their profitability, image, target market, and growth

- $\quad$ Competing with other national brand manufacturers over certain segments of the market

- Using a "pull strategy" - heavy advertising and sales promotion to reach the target market and develop a loyal customer base

- $\quad$ Innovating (thus spending large funds on R\&D), and energizing and leveraging their brands to stay ahead and expand in different product categories and different market segments. Sometimes they fall into producing private-label brands for their retailers for profits and utilization of excess capacity which may create a case of cannibalization of their national brand. 
Characteristics, concerns and strategies of retailers and their private-label brands include:

- $\quad$ Getting larger, global, and more powerful. Their power is partially attributed to what national brands they carry, so they need good relationships with manufacturers of national brands.

- $\quad$ Concerned about the profitability, store image, and market position

- $\quad$ Would like to develop strong relationships with their customers to enhance store loyalty and offer their own private-label brand to compete head-on with the national brands they carry (such store brands can be produced by the national brands manufacturers or by other manufacturers).

- Their motivation is profit, integrative growth, and the utilization of their powerful presence in the market (e.g. store loyalty, competitive position, etc.).

- They do not advertise their brand, but they advertise the store. Historically, they are not designers or innovators of new products but, rather, are imitators. However, lately they are doing more marketing activities for their store brands which is seriously impacting national brands.

- $\quad$ They are powerful in the sense of not being dependent on national manufacturers to produce their store brands.

- Their marketing expenses are lower than those of the national brands' manufacturers, and thus their margin is higher. Even their production cost is usually lower than that of national brand manufacturers, especially when $R \& D$ expenses are considered.

- $\quad$ Retailers are powerful and thus may sell national brands at relatively high prices to widen the gaps between national brands and private label brands.

- $\quad$ The retailer's size and resources enable them to invest in high-quality store brands.

- $\quad$ Retailers are also motivated to offer their own store brand to reduce dependency on the few national manufacturers (in a highly concentrated industry).

Consumer characteristics include:

- $\quad$ Price consciousness

- $\quad$ Price-quality association

- $\quad$ Consumer demographics (e.g. gender, marital status, children living at home or not, and their age(s), family size, level of education, age, occupation, ethnicity, and income)

- Consumer psychological/social/cultural factors, such as brand loyalty, level of involvement in the product category, risk taking/averting, self-consciousness, self-esteem, belonging, smart shopper perception, perception of store image, and store loyalty

- $\quad$ Other factors, such as time pressure and consumer inertia, defined as consumer reluctance to switch away from the brand purchased on a previous purchase occasion

Product categories include:

- $\quad$ Public versus private, utilitarian versus hedonic or prestige, goods versus services, and specific different product categories used in this study (over-the-counter health care products, packaged food, non-alcoholic beverages, household cleaning and washing products, paper goods, personal care products, and pet food and products)

Relevant environmental factors include:

- $\quad$ Economic conditions in general (current and future outlook), consumer confidence, social pressure, and culturally or sub-culturally motivated factors

\section{Interactive Effects/Relationships}

The national brand manufacturer creates brands and develops loyal consumers to those brands which are sold via the retailer; therefore, they should create a strong bond with the retailer (e.g. support the retailers, provide them with promotional material, etc.) to present their products to the consumer. However, they are now obliged to 
compete with the retailers who are offering the consumer an alternative, thus creating a synergistic-antagonistic relationship. This has become a major source of conflict - the retailer wants consumer store loyalty and the manufacturer wants consumer brand loyalty. Another aspect of the relationship between the manufacturer and the retailer is the issue of whether or not they should produce the private label for the retailer, creating another dilemma for the manufacturers - if they produce the private label they are cannibalizing their brand and, if they do not, they will lose the possibility of profit and the retailer will still go somewhere else and get it.

Another dilemma is for the retailer - they need the manufacturer, or the national brand, to be on their shelf to attract the consumers (they cannot afford not to have national brands on their shelves); but at the same time, given their power in the market and size, they would like to expand and grow, therefore stepping beyond their traditional responsibilities to offer alternatives to the manufacturers' brands. So, they love the manufacturer to enrich their shelves, but they love to push their own brands to improve their profits.

The consumer is being pulled in different directions. The manufacturer is trying to build a relationship with their targeted consumers by providing information, sales promotion, advertising, and quality product in an effort to gain consumer brand loyalty. At the same time, the retailer is trying to attract the same consumer to their store by inducing them not only by offering the national brand, but also by offering a lower-priced alternative, hoping to make the consumer store-loyal and buy their private brands. Today's consumer is better informed but is also being impacted by many personal variables and characteristics, making the decision-making process even more complex, especially when considered across different product categories. Consumers are torn by the love of the store, loyalty to the brand, and their personal needs, thus reducing the predictability of their purchase choice.

Manufacturers, retailers, and the consumers are all influenced by what is going on in the environment and its various components. For example, downward economic conditions impact the consumer's purchasing power and change their attitude toward buying certain brands over others, thus reducing profits for the retailer and the manufacturer, which increases the level of rivalry and aggravates the situation.

\section{METHODOLOGY}

This research study started with exploratory investigation to determine the dimensionality of the issues under consideration and included a literature review, one focus group session, and an in-depth interview with a store manager of one of the major supermarket chains in the area. The exploratory research activities assisted in identifying important factors contributing to the complexity of the situation regarding national brands versus store brands and assisted in developing the questionnaire, which was used to collect the primary data.

The first part of the questionnaire included questions about respondents' purchasing habits of store brands, frequency of purchasing, amount of purchases, reasons for purchasing store brands versus national brands, and variances across different product categories. It is to be noted that national brand and private-label or store brand, which are used interchangeably in this paper, were clearly defined in the introduction of the questionnaire. The questionnaire then asked about the importance of the store image in consumer choice of store brand and if such a decision is influenced by special situations (e.g. entertaining a guest, private versus public use of the product, level of involvement in the product category, and their self-perceptions of how smart they are in shopping, etc.). Next, respondents were asked about what national brand manufacturers and retailers could do to win their choices and about the importance of the reasons that made them purchase store brands over national brands.

The second part of the questionnaire consisted of a set of 23 attitudinal statements (applying a five-point Likert scale from 1 being strongly disagree to 5 being strongly agree) to check for response consistency and to solicit the attitude of respondents to a variety of core and related issues regarding a) their purchasing habits of store and national brands, b) their attitudes toward and preferences of both, and c) their perceptions of themselves. The last section of the questionnaire included classifying information questions, mainly demographic information. It is to be noted that most of the questions in the questionnaire were guided by and designed to test the hypotheses about the dynamics in the conceptual framework presented above. 
The research was conducted in the Inland Empire area of greater Los Angeles, Southern California. A total of 281 consumers were surveyed - 236 respondents were intercepted in malls, shopping plazas, and major grocery stores of whom 209 completed the questionnaire adequately, and 72 respondents completed the questionnaire online (via social media postings). Randomization was adequately achieved in the selection of place and time of day regarding the data collection via interception. Also, randomly, every other person was asked to complete the selfadministered questionnaire and offered an incentive of $\$ 5$ in cash for their time (online respondents were provided a chance to win one of four gift certificates of $\$ 25$ each). Participants were informed that the research was regarding their purchasing behaviors of store versus national brands, attitudes, preferences, and intentions toward purchasing store and national brands and that completion of the questionnaire was voluntary and they could stop at any time 281 questionnaires were completed adequately. Data were analyzed using SPSS. Though this sample clearly could be larger and may raise some concerns of external soundness because of the specificity of the area from where the information was collected, it can be used cautiously to verify some of the relationships in the conceptual framework.

\section{RESULTS ANALYSIS AND DISCUSSION}

\section{Sample Demographics}

A brief discussion about the demographics of the respondents is in order. The sample included 281 respondents of whom $173(61.6 \%)$ were females and 108 (38.4\%) were males; $83(29.5 \%)$ were single, $169(60.1 \%)$ were married, and the rest $29(10.4 \%)$ were divorced, widowed, or separated; $130(46.3 \%)$ reported having children living at home, with the majority of those (64.9\%) having one child and $32.4 \%$ having two or more children living at home. The sample shows that $4.4 \%$ had completed high school or had some high school education, $27.0 \%$ had some college or completed technical school, $34.2 \%$ had a college education, and 34.5\% had either a graduate or postgraduate education. It seems the sample represented is more educated than the general population of the area. As far as the ethnic composition of the sample, $46.3 \%$ were Caucasians, $25.6 \%$ were of Hispanic/Latino origin, $12.5 \%$ were African American, 9.3\% were Asian Pacific Islanders, and 6.4\% were of other ethnicities (mainly MiddleEastern white and two Native American). The age distribution of the sample was 34.5\% between the ages 18 and 35, $48.7 \%$ between the ages of 36 and 55 , and $16.7 \%$ over 56 years old. The income distribution in the sample was $35.3 \%$ made $\$ 50,000$ or less in annual household income, $40.9 \%$ earned between $\$ 50,001$ and $\$ 100,000,14.5 \%$ earned between $\$ 100,001$ and $\$ 150,000$, and $9.2 \%$ earned over $\$ 150,001$.

It is to be noted that the results of this study are based on a self-administered questionnaire (self-reporting) and may have responses with mental bias on the part of the respondent (memory lapse, exaggeration, etc.). However, the results are: $94 \%$ of respondents reported that they have bought a store brand in the last six months, but at different frequencies ("once in a while" $-31.7 \%$, "50\% of the time" $-30.2 \%$, and "regularly" - 35.6\%) and at different percentages of total purchases (" $20 \%$ or less" of their purchases $-29.2 \%$; " $21-50 \%$ " - $47.7 \%$, " $51-80 \%$ " $18.5 \%$, and " $80 \%$ or more" $-4.9 \%$ ). Results confirm the growth of store brand sales as cited in the literature.

Respondents reported the following reasons for buying store brands: lower price $(72.2 \%)$, "same quality as national brand" (47.0\%), "I do not see much difference between store brand and national brand" (41.3\%), "I trust the store" (31.3\%), "always available" (17.4\%), "I like my store" $(15.3 \%)$, and other $(6.8 \%)$. This confirms the existence of price parity between national and store brands and that the retailers are seriously improving the quality of their brands.

When cross-tabulating the frequency of purchasing store brands and the reasons for buying store brands, the results indicated that lower prices have a significant relationship with the frequency - the higher the frequency of purchasing store brands, the higher the percentage of respondents citing lower price as a reason $(\mathrm{p}=.000)$. The same holds true for those who reported they believe store brands have the same quality as national brands $(\mathrm{p}=.000)$. However, when the frequency or percentage of purchasing store brands was cross-tabulated with "I trust my store" and "I like my store" as reasons for buying store brands, there was not a significant relationship. The authors found this result a bit surprising since one of the hypothesized relationships in the literature was that consumers are more likely to buy a store brand if they trust and/or like the store. However, store name importance showed a significant relationship to the frequency of buying a store brand. Availability was not significantly related to frequency of purchasing a store brand. 
Respondents' perception of risk in buying store brands and the frequency and percentage of purchasing store brands were significantly related $(\mathrm{p}=.000)$. Those who believe that they are not taking a risk $(78.6 \%)$ reported buying store brands more frequently and at higher percentages of their total purchases than those who believe they are taking a risk. However, even those who believe they are taking a risk in buying a store brand reported buying store brands, but less frequently and at very low percentages of their total purchases.

The frequency and percentage of purchases of store brands reported were cross-tabulated with the importance of store name and both have a significant direct relationship $(\mathrm{p}=.000)$. The results show the importance of the store name in the consumers' decision to buy a store brand. Also, brand loyalty has a significant relationship with frequency $(\mathrm{p}=.003)$ and percentage of purchases $(\mathrm{p}=.000)$ of store brands. Respondents who reported themselves as brand loyal reported less frequent and lower percentage of purchases of store brands, although they still reported buying store brands once in a while. Brand loyal customers also reported buying a store brand for its lower price. It is surprising to see, however, that store loyalty did not show a significant relationship with the frequency or percentages of buying store brands.

One very important result is that brand loyal consumers (42.0\%) tend to like and trust the store they shop in (significant relationship, $\mathrm{p}=.001$ ). This result should alert manufacturers of national brands to an important fact that they still have loyal customers who value the retailers who carry their favorite national brand, helping manufacturers to gain at least a point of power over the retailers.

Respondents consider themselves as "smart shoppers"; the mean was 5.54 (std. dev. $=1.344$ ) on a sevenpoint scale, indicating the self-perceived level of awareness/knowledge of consumers. Smart shoppers tend to be brand loyal. There was not a significant relationship between the frequency of purchasing store brands and the selfperception of consumers of how smart of a shopper they are, but there is a significant relationship with the percentage of purchases of store brands and the perception of self-smartness. Smart shoppers reported buying about $20 \%$ of their purchases from store brands; a segment of them said they are brand loyal and regard variety as important, while others considered themselves to be store loyal. So, it seems that some smart shoppers consider themselves smart because they are buying store brand (value-oriented smartness), while others consider buying the national brand as smartness. Regarding respondents' beliefs that store brands are made by the same manufacturers that make the national brands, on a scale 1 to 10 the mean was 6.02 (st. dev. $=2.437$ ) with $57.3 \%$ of respondents rating being 6-10 on the scale.

As for the importance of the store name and image in their decision to buy a store brand (on a scale from 1 "not important at all" to 7 "extremely important"), the mean of the responses was 4.33 (std. dev. = 1.863 ), with $29.9 \%$ of respondents reporting very or extremely important. When asked if a financially difficult situation would lead to buying a store brand, $75.4 \%$ of the respondents reported "yes" for an answer. On the likelihood of buying a store brand or national brand if the product would be used in the presence of guests or in private versus public, the results are shown (on a scale 1 "very unlikely" to 7 "very likely") in Table 1. The purpose of this question was to see the psychology of consumers regarding social pressure or prestige.

Table 1: Likelihood of National vs. Store Brand Purchases Across Usage Situations

\begin{tabular}{lll}
\hline & Used In Presence Of Guests & Used In Private Versus Public \\
\hline Buy National Brand & Mean 4.98 (std. dev. $=1.662)$ & Mean 4.53 (std. dev. $=1.777)$ \\
Buy Store Brand & Mean 4.44 (std. dev. = 1.748) & Mean 5.17 (std. dev. = 1.636) \\
\hline
\end{tabular}

Regarding their future intentions, $97.2 \%$ of the sample said they would buy a store brand in the future and $98.9 \%$ said they were willing to try a store brand.

Through further examination via cross-tabulation of the different variables, the authors found several significant relationships, including the following:

- $\quad$ Those who buy store brands on a regular basis and at a higher percentage of their total purchases want the retailers to keep the price lower and want manufacturers of national brands to reduce their prices to attract them. 
- $\quad$ Those who claim to be store loyal want the store to improve quality, improve appearance/packaging of their private-label brands, do not want the store to advertise, and are not asking for more variety. However, customers who are not store loyal would like the store to keep the prices lower.

- $\quad$ Brand loyal customers agree that manufacturers should educate consumers and also agree - though to a lesser extent than those who are less brand loyal - that manufacturers should reduce their prices.

When asked if they were involved heavily in any product category, $53.4 \%$ of respondents reported "yes" and $74.6 \%$ of those who said they were heavily involved in a product category reported that they were willing to buy a store brand in the category in which they are heavily involved. This can be explained by two possible arguments. One is that involved consumers may not see much difference because of their knowledge in the product category and thus are willing to buy a store brand. Another possible explanation is a low perceived risk associated with buying low-ticket items such as groceries.

Regarding the importance of the reasons in determining the respondents' choice to purchase a store brand over a national brand, the results were as follows as per their importance (on a scale from 1 "Unimportant" to 7 "Very important"): quality (mean $=6.2$ and std. dev. $=1.02)$, price $(6.14$ and 1.273$)$, reliability $(5.92$ and 1.296$)$, availability (5.70 and 1.178), convenience (5.41 and 1.409), familiarity (5.16 and 1.570), variety (5.12 and 1.449), risk (4.98 and 1.698), store image (4.72 and 1.761), packaging (4.21 and 1.609), and brand image (4.08 and 1.845).

Price importance varied across customers. Those who buy store brands more frequently considered price as an important reason for buying a store brand; also, those who are heavily involved in a product category indicated price as important as well. However, brand loyal consumers gave a lower importance to price than did consumers who are less brand loyal, and the same holds true for the store loyal versus less store loyal customers.

Customers who frequently purchase store brands claimed quality as an important factor. However, the percentage of store brand purchases of their total purchases fell as the importance of quality rose. It is interesting to see the higher the importance of quality, the higher the level of brand loyalty and store loyalty - a good message to the retailer to build their customer loyalty not necessarily through their private-label brands, but through other means. However, improving the quality of their store brand will also help.

Those who considered brand image as an important factor considered themselves brand loyal and purchased store brands at a significantly lower percentage than those who did not care about brand image. Customers who claimed heavy involvement in a product category showed more importance to brand image - but also a willingness to buy store brands, though to a lesser extent than those who are not involved in a product category. The more consumers valued convenience, the more frequently they reported buying store brands and the greater their percentage of purchases of store brands; however, only up to 50\% of their purchases, but not beyond that level. At the same time, they showed higher store loyalty and also considered themselves smart shoppers (the smarter they rated themselves on the smartness scale, the higher the importance of convenience for them). Packaging was considered of significant importance to those who are brand loyal and who buy fewer store brands. Brand loyal consumers also put more importance on store image and risk in their purchases, while availability was more important to store loyal customers.

When asked to rate their tendency to buy a store brand across different product categories (on a scale from 1 "Never buy" to 5 "Always buy" a store brand), the mean of their responses is reported in Table 2 (Mean A). However, when asked if they were unable to find their national brand on the shelf, would they buy the store brand (on the same scale as above), the results indicated a greater willingness to buy the store brand in the absence of the national brand (Mean B in Table 2), with a higher mean in all cases. It is to be noted that standard deviation in both situations was higher than 1.0, indicating a major variance in the responses. 
Table 2: Tendency to Buy Store Brand Across Product Categories in Presence or Absence of National Brand

\begin{tabular}{lcccc}
\hline \multicolumn{1}{c}{ Product Category } & Mean (A) & Mean (B) & $\begin{array}{c}\text { Percentage Of Those } \\
\text { Who Rate 4 Or 5 (A) }\end{array}$ & $\begin{array}{c}\text { Percentage Of Those } \\
\text { Who Rate 4 Or 5 (B) }\end{array}$ \\
\hline Paper goods & 3.53 & 3.99 & $47.11 \%$ & $70.5 \%$ \\
Household cleaning \& washing products & 3.29 & 3.92 & $39.79 \%$ & $68.3 \%$ \\
Packaged foods & 3.04 & 3.64 & $34.1 \%$ & $56.6 \%$ \\
Over-the-counter health care products & 2.81 & 3.56 & $29.54 \%$ & $58.0 \%$ \\
Pet food and products & 2.42 & 3.25 & $25.46 \%$ & $50.5 \%$ \\
Non-alcoholic beverages & 2.32 & 3.17 & $23.11 \%$ & $41.9 \%$ \\
Personal care products & 2.32 & 3.04 & $21.23 \%$ & $38.8 \%$ \\
\hline
\end{tabular}

Table 3 shows the results of the respondents when asked what a retailer could do to make them buy the store brand and what the manufacturer could do to cause them to buy a national brand (via a "check all the apply" question).

Table 3: Consumers' Recommendations for Retailers and Manufacturers

\begin{tabular}{|c|c|}
\hline What Retailers Can Do To Make You Buy Their Brand & \% Of Respondents "Checked" \\
\hline Keep the price lower & $97.7 \%$ \\
\hline Improve quality & $65.8 \%$ \\
\hline More variety & $44.5 \%$ \\
\hline Improve appearance/package & $37.4 \%$ \\
\hline Advertise & $23.5 \%$ \\
\hline Other & $4.3 \%$ \\
\hline What National Brands Manufacturers Can Do & \% Of Respondents "Checked" \\
\hline Reduce prices & $77.6 \%$ \\
\hline Educate the consumers & $35.2 \%$ \\
\hline Innovate & $32.0 \%$ \\
\hline Improve quality & $27.4 \%$ \\
\hline Advertise more & $17.1 \%$ \\
\hline Improve packaging & $11.7 \%$ \\
\hline Other & $1.8 \%$ \\
\hline
\end{tabular}

All the variables were cross-tabulated with the respondents' demographics. Following are some significant relationships (only the significant results are reported):

Some of "what the retailers can do" includes:

- $\quad$ Large size households want the store to keep lower prices.

- $\quad$ Younger consumers say to improve appearance/package.

- $\quad$ Single respondents want them to advertise.

- Low-income households want them to offer more variety in their store brand.

Further, "what manufacturers can do" includes middle income respondents, middle age, and households with no children want them to innovate and improve quality and large size households want them to reduce prices.

Across product categories, most consumers reported they would buy a store brand of all categories. An example of a significant relationship includes consumers who buy OTC health care products but with less percentage of their total purchases. Consumers who are characterized as "not loyal to any brand, smart shoppers, married, are highly educated, or middle aged" all have a higher tendency to buy store brands of OTC health care products. One explanation for this result is that drug stores predominantly offer private label or store brands, which is where people mostly buy such products. Also, females and families of small size tended to buy store brands of OTC health care products on a regular basis. Additionally, consumers who are heavily involved with a brand reported they would definitely buy a store brand of OTC health care products, as well as personal care products. Middle age consumers tended to buy more store brands of personal care products. Large size households, Asians and Hispanics/Latinos, and younger consumers favor store brands in the household cleaning products category. Brand loyal consumers buy less of store brands in packaged foods and will buy store brands of cleaning products and paper 
goods, but less frequently. Families with kids under six years of age and young adult individuals tended to buy more store brands of packaged food products. Young individuals tended to buy more store brands of household cleaning and washing products. This is in line with the result that they tended to buy a store brand if it would be used in private. At the same time, they tended to claim that they are smart shoppers.

Married couples tended to buy more store brands of paper goods and they were also more likely to be brand loyal than single or divorced individuals. However, they were more likely to buy a store brand than single individuals when a guest is coming over. Also, the smaller the family size, the more likely they were to buy a store brand. Families of small size and young adult individuals placed more importance on the store name in their decision to buy store brands. Females tended to believe that store brands are produced by the same national brand manufacturers than did their male counterparts; the same belief is reported by lower income consumers versus other income groups. Females were more likely to buy a store brand than males when a guest is coming over.

Customers with children at home had a higher tendency to buy store brands with frequency "once in a while" or " $50 \%$ of the time" and, to a lesser extent, "regularly". The larger the household size, the more frequently and larger percentage of purchases were of store brand products. Single customers did not see much difference between store and national brands. Middle age consumers showed higher frequency of purchasing store brands versus young and older respondents. Customers of lower income households claimed to be smart shoppers. Caucasians and customers of Hispanic/Latino origin showed frequency and percentage to a certain extent (up to about $40 \%$ of purchases) of store brands versus other ethnicities. However, they were more likely to buy national brands if guests were visiting. African-American customers and those of Hispanic/Latino origin responded "yes" to buying store brands if faced with difficult financial circumstances. Customers of Hispanic/Latino origin tended to be more involved in certain product categories than did other ethnic groups.

When asked about the importance of the reasons that determine their choice of store brand over national brand, the following observations were found significant:

- $\quad$ Married individuals rated risk and variety as very important reasons for buying store brands.

- $\quad$ Larger sized household, married respondents and middle age respondents rated price as very important.

- $\quad$ Quality was more important for females than it was for males.

- $\quad$ Customers of Hispanic/Latino origin and Asians valued brand image highly. Interestingly, large size households, younger respondents, and customers of Hispanic/Latino origin and African Americans rated convenience as very important.

- African-American customers also reported less importance to "trust in the store" as a reason for buying store brands.

- $\quad$ Large size families, highly educated respondents, and younger consumers valued familiarity as important.

- $\quad$ Small size households, younger respondents, and lower income families rated availability of products as very important, while the store image was significantly important to middle income households.

Following are some significant results when attitudinal responses were cross-tabulated with the demographics of respondents.

- $\quad$ Respondents of low income households reported that they buy store brands because of the lower price and that they buy national brands when buying less frequently purchased items.

- $\quad$ Single consumers, divorced, and Asians tended to buy national brands because they enhance self-esteem.

- Married individuals, middle age, and Hispanics/Latinos tended to buy national brands because they enhance their life style.

- $\quad$ Married individuals believed national brands are of better quality.

- $\quad$ More educated consumers considered national brands more innovative. 


\section{CONCLUSION AND RECOMMENDATIONS}

Inspired by the holistic marketing concept (Kotler \& Keller, 2012) whereby marketing programs, processes, and activities are developed with recognition of interdependencies, where everything matters and where an integrative perspective is often necessary, the authors developed a conceptual framework to assist stakeholders in understanding the dynamics of the national versus store brand global phenomenon. Such understanding can help stakeholders accurately assess the implication of each strategic move on other stakeholders in the short- and longrun and may reduce the possibility of making decisions that exhaust resources for them and others.

For manufacturers of national brands, the message is clear - do not panic; rather, continue sharpening your marketing strategies. The results largely confirm what is generally known about consumers - they are conscious of brands and their significance and continue to be passionate about buying branded goods because they still feel that they perform better (have higher quality) than private label products and satisfy their specific needs and wants. Consistent with this pattern, consumers are willing to pay more for branded products and they see specific national brands as reflective of their needs, ego, values, and characteristics. Although the authors agree with the recommendations cited in the literature - such as innovating new products not easily copied by the private labels, finding new distribution channels for branded goods, building strong brand images that consumers find relevant, launching flanking brands that compete on price, developing alliances with retailers and other manufacturers to create products, and even becoming the producers of the private label goods themselves - the authors caution that adopting such strategies should be done so only within the context of a thorough analysis of their implications within the larger conceptual framework.

The results of the research indicate it would be valuable for manufacturers to better understand their targeted consumers. This research study, as well as previous research cited in the literature, showed that the decision to buy a national versus private label brand is attributed to individual differences such as involvement, consumer loyalty, price consciousness, demographics, psychographics, etc. and that such differences also vary across product categories. Many of these differences, some of which may also be influenced by environmental factors, showed significant relationships that determine the consumer's choice between national and private label brands.

Retailers have incentives to give priority to their private label brands because of the generous margins and the favor they gain from their customers by offering value alternatives. The literature indicates that private-label brands are here to stay and the recommendations cited to the retailers are to continually improve and maintain quality, to keep the prices reasonable, to broaden the product line, and to market aggressively. Some of these strategies should be implemented carefully. The results indicate that the retailers' tactic of using aggressive marketing to develop customers who are loyal to their private label brand as a means to enhance store loyalty does not hold. Store-loyal customers may buy the store brand, but they do not develop store-brand loyalty. The research suggests the other way around. Given this finding, retailers should focus on their core business of retailing, developing strong customer relationships, and improving store image through other means (customer service, assortment, purchasing experience, etc.) to develop more store loyalty, rather than exhausting resources in an attempt to develop customer loyalty to their private label brands to improve store image and attract customers.

While the authors favor cooperation rather than conflict between manufacturers and retailers, they warn against possible collusion in the process of appeasing each other - by having national brand manufacturers produce store brands for retailers to profit and to please the retailer and develop good relationships with them. This strategy may induce the retailer to keep perhaps two national brands on the shelf alongside their private label and thus disadvantage small manufacturers and reduce choices for customers. This may be interpreted as curtailing competition, hurting consumers in the long-run, and causing consumer advocates to voice their concerns.

It is to be noted that the study is limited - based on respondents' self-reporting of attitudes, preferences, and intentions rather than tracking actual behavior; limited geographic scope; and small sample size for such consumer research study. Therefore, results should be used cautiously and further research is warranted to study the stakeholders and their relationships with others within the framework and its dynamics. 


\section{AUTHOR INFORMATION}

Elias G. Rizkallah is currently a Professor of Marketing and Coordinator of the Management and Marketing Program at the Zapara School of Business, La Sierra University, Riverside, California. Rizkallah has a Ph.D. in Marketing from J. L. Kellogg Graduate School of Management, Northwestern University. Research interests include strategic marketing planning, consumer behavior, and international marketing. Rizkallah has served nineteen years in academic positions at various universities and an additional twelve years in international marketing consulting and line management. E-Mail: erizkall@lasierra.edu.

Heather K. Miller is M.B.A. advisor and co-manager of the Executive Education Program at La Sierra University's Zapara School of Business where she also serves as an adjunct faculty in management. Her professional career has included writing, editing and public relations, and more than a decade of involvement with social entrepreneurship.

Miller earned her M.B.A. in general management from La Sierra University. Her research interests include consumer behavior and motivation, sustainable development, personal growth, and self-worth. E-Mail: hmiller@lasierra.edu.

\section{REFERENCES}

Ashley, S. (1998). How to effectively compete against private-label brands. Journal of Advertising Research, 38(1), 75-82. Batra, R. (2000). Consumer-level factors moderating the success of private label brands. Journal of Retailing, $76(2), 175$.

Berkowitz, D., Bao, Y., \& Allaway, A. (2005). Hispanic consumers, store loyalty, and brand preference. Journal of Targeting, Measurement and Analysis for Marketing, 14(1), 9-24.

Breneiser, J., \& Allen, S. (2011). Taste preferences for brand name versus store brand sodas. North American Journal of Psychology, 13(2), 281-290.

Corstjens, M., \& Lal, R. (2000). Building store loyalty through store brands. Journal of Marketing Research, 37, $281-291$.

Erdem, T., Zhao, Y., \& Valenzuela, A. (2004). Performance of store brands: A cross-country analysis of consumer storebrand preferences, perceptions, and risk. Journal of Marketing Research, 41, 86-100.

Geyskens, I., Gielens, K., \& Gijsbrechts, E. (2010). Proliferating private-label portfolios: How introducing economy and premium private labels influences brand choice. Journal of Marketing Research, 47, 791-807.

Goldsmith, R., Flynn, L., Goldsmith, E., \& Stacey, E. (2010). Consumer attitudes and loyalty towards private brands. International Journal of Consumer Studies, 34, 339-348.

Horvat, S. (2011). Influence of consumer and category characteristics on private label attitudes and purchase intention in emerging market: A conceptual model. International Journal of Management Cases, 13 (4), 191-198.

Kotler, P., \& Keller, K. (2012). A Framework for Marketing Management (5 ${ }^{\text {th }}$ ed.), (p. 10). Upper Saddle River, NJ: Prentice Hall.

Lamey, L., Deleersnyder, B., Dekimpe, M., \& Steenkamp, J. (2007). How business cycles contribute to private-label success: Evidence from the United States and Europe. Journal of Marketing, 71, 1-5.

Liu, T., \& Wang, C. (2008). Factors affecting attitudes toward private labels and promoted brands. Journal of Marketing Management, 24(3-4), 283-298.

Pandya, A., \& Joshi, M. (2011). A comparative study on consumers' attitude towards private labels: A focus on Gujarat. The IUP Journal of Marketing Management, 10(1), 19-34.

Parker, P. (2006). Befriending the private label. Harvard Business Review, 84(2), 61-62.

Quelch, J., \& Harding, D. (1996). Brands versus private labels: Fighting to win. Harvard Business Review, 74(1), 99-109.

Richardson, P., Jain, A., \& Alan, D. (1996). Household store brand proneness: A framework. Journal of Retailing, 72(2), 159-185.

Semeijn, J., Riel, A., \& Ambrosini, B. (2004). Consumer evaluation of store brands: Effects of store image and product attributes. Journal of Retailing and Consumer Services, 11, 247-50.

Seuffert, M. (2009). Are private labels a double-edged sword? Aftermarket Business, October, 74.

Shetty, A., \& Manoharan, S. (2012). The battle of private and national brands: Strategies to win a losing battle against the private brands in India. The IUP Journal of Business Strategy, 9(3), 32-45.

Steenkamp, J., Van Heerde, H., \& Geyskens, I. (2010). What makes consumers willing to pay a price premium for national brands over private labels? Journal of Marketing Research, 47, 1011-1024. 